\title{
FORTALECIMENTO DA IDENTIDADE E CUIDADO EM SAÚDE: PERSPECTIVAS DA BIODANÇA NA COMUNIDADE
}

IDENTITY STRENGTHENING AND HEALTH CARE: PERSPECTIVES OF BIODANZA IN THE COMMUNITY

FORTALECIMIENTO DE LA IDENTIDAD Y ATENCIÓN A LA SALUD: PERSPECTIVAS DE LA BIODANZA EN LA COMUNIDAD

Vanessa Bezerra da Cunha ${ }^{1}$

Rose Danielle de Carvalho Batista ${ }^{2}$

Camila Siqueira Cronemberger Freitas ${ }^{3}$

Palavras-chave:

Promoção da Saúde; Atenção à Saúde; Terapias Complementares; Biodança.

Keywords:

Health Promotion; Health Care; Complementary Therapies; Biodanza.

Palabras clave: Promoción de la Salud; Atención a la Salud; Terapias Complementarias; Biodanza.

Submetido: 04 de Fev. de 2020

Aprovado: 18 de Nov. de 2020

Autor(a) para Correspondência: Vanessa Bezerra da Cunha R. João Domingos Ramos, 2846 Parque Ideal - Teresina, PI CEP: $64078-750$ E-mail: vanessacunha88@hotmail.

\section{RESUMO}

Este estudo teve por objetivo compreender o fortalecimento da identidade e o cuidado em saúde por meio da prática da biodança na comunidade. A pesquisa de campo, de abordagem qualitativa com caráter descritivo exploratório, foi realizada mediante observação participante, entrevistas semiestruturadas e análise de diário de campo em um centro social em Teresina-PI, tendo como foco o Grupo de Biodança Aflorar. Evidenciou-se que a biodança fortalece o processo de reconhecimento e identidade do sujeito, trazendo benefícios em termos de relaxamento e renovação pessoal e ampliação da conexão entre pares, potencializando a comunicação e a autonomia das pessoas. Também se percebe que a visão do cuidado em saúde é ampliada por meio de maior compreensão de seus corpos e suas vivências, possibilitando não só a busca da prevenção, mas a melhoria da qualidade de vida. Constatou-se maior conscientização a respeito da integração das pessoas consigo e com o mundo ao seu redor, indicando que a vivência da biodança, de modo regular, facilita essa compreensão mais integrada da vida.

1. Psicóloga. Aluna de Especialização em Saúde da Família e Comunidade na Universidade Estadual do Piauí (UESPI). E-mail: vanessacunha88@hotmail.com 0RCID: https://orcid.org/0000-0001-6074-4261

2. Psicóloga. Mestra em Saúde da Família pela Universidade Federal do Piauí (UFPI).E-mail: rosecarvalhobatista@ yahoo.com.br ORCID: https://orcid.org/0000-0003-0921-3750

3. Psicóloga. Mestra em Educação pela UFPI. E-mail: camilasiqueirapsi@gmail.com 0RCID: https://orcid.org/00000003-2771-5949

Certificação de redação científica: E.L.Freire Editora. Edição de texto: Evandro L. Freire. Revisão de provas: Texto definitivo lido e validado pelas autoras. 


\section{ABSTRACT}

This study aimed to see identity strengthening and health care through the practice of biodanza in the community. The field research, with a qualitative approach and an exploratory descriptive nature, was carried out through participant observation, semi-structured interviews, and field diary analysis at a social center in Teresina, Piaui, Brazil, focusing on the Aflorar Biodanza Group (Grupo de Biodança Aflorar). It became clear that biodanza strengthens an individual's recognition and identity process, bringing benefits in terms of relaxation and personal renewal and increased connection between pairs, enhancing people's communication and autonomy. It is also clear that the health care view is broadened through a greater understanding of their bodies and their experiences, enabling not only the search for prevention, but improved quality of life. Greater awareness was found regarding people's connection to themselves and the world around them, indicating that contact with biodanza, on a regular basis, facilitates this more integrated view of life.

\section{RESUMEN}

Este estudio tuvo como objetivo comprender el fortalecimiento de la identidad y la atención a la salud a través de la práctica de la biodanza en la comunidad. La investigación de campo, con un enfoque cualitativo y un carácter exploratorio descriptivo, se realizó mediante observación participante, entrevistas semi-estructuradas y análisis de diario de campo en un centro social ubicado en Teresina, Piauí, Brasil, con foco en el Grupo de Biodanza Aflorar. Quedó claro que la biodanza fortalece el proceso de reconocimiento e identidad de un individuo, brindando beneficios en términos de relajación y renovación personal y una mayor conexión entre parejas, mejorando la comunicación y la autonomía de las personas. También es claro que la visión asistencial se amplía a través de una mayor comprensión de sus cuerpos y de sus vivencias, posibilitando no solo la búsqueda de la prevención, sino una mejor calidad de vida. Se encontró una mayor conciencia sobre la conexión de las personas con ellas mismas y el mundo que las rodea, lo que indica que el contacto con la biodanza, de manera regular, facilita esta comprensión más integrada de la vida.

\section{INTRODUÇÃO}

Ao longo da história, a noção de cuidado em saúde foi ressignificada para abranger as necessidades das pessoas de modo ampliado, avançando concomitantemente com o conceito de saúde da população. Curar, tratar e controlar se tornam posturas limitadas no âmbito da saúde, pois essas práticas supõem uma relação estática, individualizada e individualizante dos sujeitos-alvo de nossas intervenções ${ }^{1}$.

Esse entendimento se deu junto com os avanços de um novo paradigma a partir do enfoque político e técnico para a compreensão e intervenção diante do processo saúde-doença-cuidado ${ }^{2}$. Cuidar da saúde de alguém significa mais do que construir um objeto e intervir sobre ele, haja vista que, para cuidar, deve-se considerar e construir projetos, assim como sustentar, ao longo do tempo, certa relação entre a matéria e o espírito, o corpo e a mente, moldada a partir do modo como o sujeito se apresenta no mundo ${ }^{1}$. 0 cuidado deve pautar-se por um compromisso com as singularidades e pluralidades do ser que o recebe, considerando todo o contexto histórico-social no qual ele está inserido ${ }^{3}$.
Diante disso, a inclusão das propostas do movimento pela promoção da saúde na agenda dos gestores públicos constitui uma preocupação governamental no setor saúde, pois nesses momentos se pode construir o ideário conjunto de uma saúde pública que garanta a qualidade e efetividade de suas ações².

Na chamada Carta de 0ttawa, a promoção da saúde é compreendida como um processo que visa a capacitar a comunidade com vistas à atuação para a melhoria de sua qualidade de vida e saúde, fomentando uma participação qualitativa no controle de tal processo ${ }^{4}$. Nesse sentido, ratifica-se a concepção expressa na Carta de 0ttawa ao garantir oportunidade a todos os cidadãos para fazer escolhas mais favoráveis à saúde. Uma dessas ações é o fomento às práticas integrativas e complementares (PIC), de modo a maximizar a política de promoção da saúde 5 .

As PIC têm o propósito de ampliar o acesso e envolvem abordagens que buscam estimular os mecanismos naturais de prevenção de agravos e recuperação da saúde por meio de tecnologias eficazes e seguras, com ênfase na escuta acolhedora, no vínculo terapêtico e na integração do ser humano com o meio ambiente e a sociedade ${ }^{6}$. 
Nessa diversidade das PIC se insere a biodança, que tem se mostrado uma aliada na promoção da saúde humana. Atua buscando a diminuição de crises de transtornos mentais e o controle de doenças, como diabetes mellitus e hipertensão arterial, tendo em vista que potencializa os aspectos ainda saudáveis das pessoas que a praticam ${ }^{7}$.

$\mathrm{Na}$ biodança há renovação existencial, que tem o mesmo sentido da autopoiese, pois as transformações ocorrem tanto em nível biológico quando observamos a melhora da qualidade da saúde física e mental, quando percebermos que as pessoas se revelam mais integradas consigo mesmas, mais harmonizadas e felizes - quanto no plano social, quando as pessoas buscam maior integração com os outros e com o ambiente à sua volta ${ }^{8}$.

Este estudo se justifica pelo impacto social da biodança na vida das pessoas, sendo uma PIC que garante aos indivíduos a ampliação da perspectiva de seus corpos e suas expressões no mundo, fortalecendo suas identidades. Também parte da preocupação de que não há estudos que tratam dessa questão no contexto local, configurando-se como uma iniciativa que amplia a compreensão do impacto dessa prática enquanto cuidado em saúde dentro de um grupo terapêutico e de como ela vem sendo significada e direcionada no cenário estadual.

Assim, este estudo teve por objetivo:

- Compreender o fortalecimento da identidade e o cuidado em saúde por meio da prática da biodança na comunidade.

\section{METODOLOGIA}

Utilizou-se o referencial teórico-metodológico da pesquisa de campo com abordagem qualitativa e caráter descritivo exploratório, buscando responder questões particulares a partir da realidade vivenciada, descrevendo as características dos fenômenos e desenvolvendo conceitos e ideias mais precisos e aprofundados $\mathrm{s}^{9,10}$.

0 estudo foi realizado no Centro Social do Cristo Rei, em Teresina-PI, tendo como foco o Grupo de Biodança Aflorar, que realizava atividades de promoção, prevenção e matriciamento junto à população, em território de vivência da Residência Multiprofissional em Saúde da Família e Comunidade da Universidade Estadual do Piauí (RMSFC/UESPI), onde atuavam os pesquisadores.

Participaram da pesquisa 12 membros do Grupo de Biodança Aflorar, maiores de 18 anos, de ambos os sexos, com assiduidade igual ou superior a 12 encontros, entre agosto de 2018 a agosto de 2019. A fim de respeitar seu sigilo, cada participante foi denominado "biodançante" de acordo com a sequência das entrevistas: Biodançante 1 a Biodançante 12.

Para a produção de informações, partiu-se de uma caracterização sociodemográfica, que abrangeu as variáveis sexo, idade, religião, escolaridade, estado civil, renda e instituição vinculada. As entrevistas, por sua vez, gravadas em áudio e posteriormente transcritas, seguiram um roteiro baseado em questões acerca da percepção de si, do sentimento dentro do grupo, do entendimento sobre cuidado em saúde, dos benefícios da biodança e da relação desta com o cuidado em saúde.

0 s dados foram submetidos às técnicas da Análise de Conteúdo ${ }^{11}$, que visa a obter, por procedimentos sistemáticos e objetivos de descrição das mensagens, indicadores que viabilizaram a inferência de conhecimentos relativos às condições de produção/ recepção das mensagens, via pré-análise, tratamento dos resultados e inferência/interpretação dos achados - esta última à luz do arcabouço teóricometodológico da psicologia comunitária e da biodança.

0 projeto foi aprovado, sob o Parecer $n$. 3.286.836/2019, pelo Comitê de Ética em Pesquisa do Centro de Ciências da Saúde da Universidade Estadual do Piauí (CCS/UESPI), cumprindo todos os preceitos éticos das Resoluções ns. 466/2012 e $510 / 2016$ do Conselho Nacional de Saúde (CNS) ${ }^{12,13}$.

\section{RESULTADOS E DISCUSSÕES}

Após análise de informações, estabeleceramse as seguintes categorias: a) Identidade como possibilidade de reconhecimento de si; b) Pertencimento grupal como possibilidade de conexão com outros; c) Cuidado em saúde; d) Benefícios da biodança; e e) Biodança e o cuidado em saúde. A seguir, apresentamos o perfil sociodemográfico dos participantes e analisamos as categorias.

\section{$\mathrm{Na}$ biodança há renovação existencial, que tem o mesmo sentido da autopoiese...}




\section{Perfil sociodemográfico}

0s 12 entrevistados tinham entre 36 e 62 anos, sendo 11 do sexo feminino e 1 do sexo masculino. Metade deles havia concluído o Ensino Médio e a outra metade se dividia equitativamente entre Ensino Médio incompleto e Ensino Superior completo. Quanto à renda familiar, apenas 1 não tinha renda mensal fixa, sendo dependente dos pais, outro recebia 1 salário mínimo e os demais declararam receber 3 ou mais salários mínimos, sendo estes aposentados. No tocante ao estado civil, 7 dos entrevistados eram divorciados, havendo 1 solteiro, 1 casado e 1 viúvo. Em relação à orientação religiosa, 11 se declararam católicos e apenas 1 dos participantes se apresentou como espírita simpatizante.

\section{Identidade como possibilidade de} reconhecimento de si

Esta categoria trouxe a percepção dos entrevistados a respeito de si e de que modo eles se sentiam diante dessa percepção. Sobre esse aspecto surgiram 4 núcleos de sentido. 0 primeiro em relação a sentimentos de ambivalência quanto às suas identidades, apresentando ora sentimentos positivos, ora negativos a respeito de si.

Tranquila, coração grande, coração bom, que gosta de ajudar [...] Sensivel, pequena no meio dos outros, dura, discriminada. (Biodançante 1)

Falar sobre identidade é remeter-se a um processo de metamorfose, de transformação de papéis, representado por cada sujeito no âmbito de condições materiais, históricas e culturais, configurando dualidades e não linearidades no conceito de $\mathrm{si}^{14}$.

0 segundo núcleo de sentido diz respeito ao reconhecimento de que, embora a vida trouxesse dificuldades, eles conseguiam ter uma visão positiva sobre si.

Me sinto uma pessoa realizada, prestativa, humana, pessoa de caridade. Gosto de ajudar. (Biodançante 2)

Calma, pés no chão, entendida de tudo. Sei perdoar, reagir, entender as pessoas. Não guardo rancor, não gosto de solidão. (Biodançante 5)

Há uma compreensão de identidade na perspectiva

\section{A saúde pode ser definida como um conjunto de capacidades para a vida.}

da biodança como uma essência invariável, mas ao mesmo tempo sendo transformada constantemente, o que corrobora as falas dos entrevistados no sentido de que eu venho mudando e continuo sendo eu mesmo. Desse modo, a identidade sempre é única, mas muda de aspecto com o passar do tempo ${ }^{15}$.

Também há a percepção de uma visão negativa sobre suas vidas e sobre como eles se reconhecem trazendo sentimentos densos, de vivências difíceis e que ainda hoje repercutem na autoimagem e autopercepção:

À procura de respostas. Me olho e tem muita coisa que é difícil. Tento ser agradável, sou humana, não sou santa. (Biodançante 3)

Eu sou uma pessoa assim... Não sei botar para fora tudo. Cuidadora. Não consigo dizer que não quero, não aceito. Ainda estou dura. (Biodançante 7)

A saúde pode ser definida como um conjunto de capacidades para a vida, de enfrentamento de riscos que habilitam a pessoa para o cuidado de si e do outro ${ }^{16}$. Dentro dessas inúmeras capacidades, a crítica e a autocrítica do ser humano se tornam condições de aproximação com suas tendências, ações e autoimagem, possibilitando uma leitura assertiva acerca dos acontecimentos, das dores e dos conflitos da vida, o que, por sua vez, pode tornar as circunstâncias modificáveis a partir de uma atitude ativa, desfazendo a rigidez conceitual e os nós afetivos que limitam o autoconceito e as posturas estereotipadas de si.

Outro fato interessante foi a percepção de si por meio do olhar da religião, buscando um reconhecimento via elementos religiosos, e da explicação dos fenômenos do cotidiano, ajudando a reduzir as angústias vivenciadas. Constatou-se em um estudo que, embora a investigação da religião do usuário não constitua uma prática rotineira ou pautada por procedimentos do atendimento/ 
acolhimento pela maioria dos profissionais entrevistados, é notória uma percepção geral de que a religião influencia o modo da pessoa cuidar da própria saúde ${ }^{17}$.

Eu sou a imagem e semelhança de Deus. Eu tenho que me ver, eu tenho que ser o espelho de luz para os outros. (Biodançante 8)

Fui muito católica, pessoa que tá sempre de bem com a vida. Acredito muito que o pensamento positivo resolve as questões. (Biodançante 12)

A experiência religiosa faz parte da caminhada de uma vida plena de sentido, onde o ser humano explora a força de sua dimensão espiritual, o que permite ser conduzido por uma realidade que o supera, captando essa dinâmica na própria consciência ${ }^{18}$.

\section{Pertencimento grupal como possibilidade de conexão com outros}

0s entrevistados trouxeram à tona a importância da participação no grupo e o modo como eles se sentiam diante deste, demonstrando o fortalecimento da união entre si, uma vez que se viam acolhidos dentro do grupo, com efetivo sentimento de pertencer a um lugar, um espaço onde podem ser quem são:

Um grupo que tá dando suporte [...] Aprendizado maior da aceitação do outro. (Biodançante 3)

Gosto muito, acho melhor que esses grupos da igreja. 0 grupo é mais humano. Já notei que todo mundo, todos são iguais, tanto faz ter emprego ou não ter, ser preta, branca. (Biodançante 7)

Ratificando as falas dos entrevistados, para Rolando Toro, a identidade se faz potente apenas por meio do "outro": EU me faço presente na presença do TU. Isso significa que a identidade, a vivência de si, forma-se e afirma-se com a "convivência". Daí o poder do grupo, de geração de vínculo afetivo, propiciando a integração e o fortalecimento da identidade ${ }^{14}$.

A identidade é desenvolvida via experiência. A experiência de sentir-se vivo aprimora o trabalho da unidade do corpo com suas sensações e emoções. Ao trabalhar em grupo, incentiva-se a abordagem

\section{...praticar \\ a escuta ativa \\ é uma forma de \\ cuidar...}

do autoconhecimento por meio do próprio corpo e a consciência de ser diferente ${ }^{19}$.

\section{Cuidado em saúde}

Essa categoria figurou com sentidos múltiplos, desde a noção de urgência em saúde, com a ideia de remediar os danos sofridos e a impossibilidade de enxergar para além do curativo, até o cuidado preventivo, com vistas às precauções:

Sou muito cuidadosa com as outras coisas, mas comigo mesmo eu acho que não. Não cuido de mim, só busco urgência. Eu não sou muito de ir para um posto de saúde, de fazer check up. Eu não ligo muito para isso, essa saúde. (Biodançante 1 )

Esse cuidado emergencial se dá com quem demonstra precisar de apoio, quando se isola ou quando busca atendimento médico para males psicológicos ou psiquiátricos. Desse modo, praticar a escuta ativa é uma forma de cuidar, de abrir-se ao diálogo ao se permitir cuidar e ser cuidado, em uma ação recíproca ${ }^{20}$, redimensionando a autonomia e oportunizando a si e ao outro para além da escuta, a recriação de seu modo de estar no mundo, sendo potencializador da vida e promovendo saúde ${ }^{21}$.

0 estímulo a o autocuidado, nesse sentido, mostrase fundamental para ampliar o próprio cuidado em saúde e incentivar a capacidade do sujeito de ver-se ativo nesse processo, não por meio de algo dado, mas reconhecido em si, corroborando o sentido ético e de valores da promoção da saúde ${ }^{22}$.

Quanto ao cuidado preventivo, foi trazida a importância de realizar exames anualmente, participar de propostas que ampliassem a esfera do cuidado para além dos centros de saúde, como atividades físicas, participar de grupos facilitadores da interação social e adotar práticas de estilo de vida que favorecessem uma vida mais ativa e 
saudável, como alimentação balanceada e atividades que promovessem o cuidado com a saúde mental:

Tomar precauções de fazer as suas avaliações todo ano [...] Vou ao médico todos os anos fazer o check up. (Biodançante 2)

Participar das coisas boas que aparecem nas nossas vidas como biodança, ginástica, cursos, coisas que interagem com o povo, com a sociedade, com o próximo, que faz bem também para si... É a convivência. (Biodançante 5)

Para cuidar, há que se sustentar uma relação entre a matéria e o espírito, o corpo e a mente, moldados a partir de uma forma que o sujeito quer se opor à dissolução de sua presença no mundo. A atitude "cuidadora" precisa expandir-se mesmo para a totalidade das reflexões e intervenções no campo da saúde $\mathrm{e}^{20}$.

Outros entrevistados trouxeram em seus discursos a busca de alternativas que ampliassem o cuidado meramente curativo ou preventivo, que auxiliassem na relação corpo-mente-espírito, favorecendo a integração com os outros, com o meio ambiente e consigo. Uma noção de cuidado como possibilidade de empoderamento do sujeito, saindo da perspectiva dos indivíduos apenas serem cuidados e buscarem ativamente esse processo:

Trabalhar o corpo [...] não ficar ociosa. Se socializar com outras pessoas, com a família. Fazer check ups, exames. (Biodançante 4)

Cuidado em saúde é muito amplo. É uma coisa assim interna. Você querer e poder. É tipo empoderamento que estão chamando agora. (Biodançante 12)

0 empoderamento representa a radicalização dos princípios básicos do modelo da aderência, propondo uma revisão profunda da estrutura das relações de assistência médica. Nesse sentido, a autonomia individual e a capacidade de fazer escolhas informadas são ideias-chave no discurso sobre 0 empoderamento ${ }^{23}$.

Outro olhar surgido nas falas foi a importância do cuidado em saúde como possibilidade da manutenção da vida e da sua qualidade:

Acho importante demais para ter uma qualidade de vida melhor. (Biodançante 10)
Fundamental, pra gente envelhecer com qualidade mantendo a qualidade de vida. (Biodançante 11)

Sobre esse aspecto, as condições de saúde melhoram a qualidade de vida, aumentando o desejo de viver, ajudando a se sentir integrado ao mundo, promovendo a experiência com autonomia e a renovação existencial ${ }^{18}$.

\section{Benefícios da biodança}

No tocante a esta categoria, um dos núcleos de sentidos foi a melhora da autoestima e o consequente sentimento e vontade de autocuidado, de autovalorização, aceitação, resgate de si:

Elevou minha autoestima, querer me cuidar, me amar, me valorizar. Resgatou o que estava morrendo dentro de mim, sabe?... Essa alegria, o abraço. (Biodançante 1) Melhora assim a minha autoestima. (Biodançante 4)

A biodança trabalha o inconsciente vital, lidando com a transformação na memória celular e dos órgãos em busca do equilíbrio, da saúde e da vitalidade, facilitando uma melhor relação consigo e com os outros, aceitando desafios e mudanças e levando as pessoas a assumir um comportamento positivo ${ }^{24}$.

Outro benefício referido por meio da prática de biodança foi a sensação de bem-estar, relaxamento e renovação física, emocional e espiritual relatada pelos entrevistados. Eles também salientaram a melhora da qualidade do sono, embora não experimentassem a insônia enquanto patologia, mas por meio dessa sensação de renovação completa, o corpo conseguia entrar em sintonia com o ambiente mais facilmente, proporcionando momentos de leveza e relaxamento:

\section{0 empoderamento representa a radicalização dos princípios básicos do modelo da aderência...}


É tipo assim uma terapia. A gente tem aquele relaxamento. (Biodançante 2)

[...] A me soltar, a falar, a parte do relaxamento. Eu saio daqui renovada! Durmo bem, apesar de nunca ter tido problemas com insônia, mas tem noite que você dorme melhor. E essa é uma das noites nas quartas-feiras. (Biodançante 4 )

A biodança tem uma proposta de reeducação para o estilo de viver, que propicia o desenvolvimento do autocuidado, expresso em um estilo de alimentação mais saudável, na prática regular de exercícios físicos e/ou de exercícios para relaxamento, no equilíbrio entre trabalho e lazer, em maior flexibilidade para lidar com as situações cotidianas ${ }^{25}$.

Outra questão suscitada pelos entrevistados foi a conquista de uma interação mais genuína com as demais pessoas, facilitando a convivência comunitária e, por conseguinte, a fluidez e autenticidade na comunicação:

É bom pra gente interagir com as pessoas, saber sair daquela timidez, a gente ser mais aberta. Além de interagir com as pessoas... a minha saúde física e mental. A convivência. (Biodançante 5)

É me amar. Acho que eu me comunicar. (Biodançante 6)

A potência do encontro emerge nas vivências de biodança como facilitadora de conexão e integração com o meio, desbravando barreiras internas que dificultavam o contato consigo e com os outros. Fato este percebido a partir do momento em que os biodançantes se colocaram à disposição para vivenciar outras experiências, conseguiram adentrar seus universos internos e viram uma possibilidade de expansão de si por meio do contato com outras pessoas ${ }^{18}$.

Outro benefício mencionado foi a possibilidade de entrarem em contato com os próprios sentimentos, facilitando o aflorar de conteúdos mais profundos, de modo maduro e trazendo aprendizado emocional durante as vivências e fora delas:

Participar de um grupo como a biodança que não só ajuda no físico, mas ajuda no emocional, na vivência, na convivência. (Biodançante 3)

\section{A biodança tem \\ uma proposta de reeducação para \\ o estilo de viver...}

Valoriza as pessoas, todo mundo lá tem valor no grupo. A parte emocional, eu acho que ela trabalha mais. (Biodançante 7 )

A afetividade é relação de alteridade, é a possibilidade de encontrar ressonância para 0 desabrochar do potencial, é o estabelecer da identidade. Desse modo, só a identidade integrada possibilita relação de alteridade, de modo que amar e expressar afeto passam a ser um grande aprendizado ${ }^{26}$.

A biodança traz o imperativo da autorregulação em um âmbito físico, corpóreo, fisiológico, na ascensão do ser universal, sugere a importância daquilo que é um diferencial da sua abordagem terapêutica - a vivência, o encontro - e potencializa sua ação ${ }^{27}$.

\section{Biodança e o cuidado em saúde}

Ao serem questionados sobre como percebem a relação entre biodança e cuidado em saúde, os participantes trouxeram algumas considerações sobre a forma terapêutica dessa relação, a qual promove evolução do corpo e da mente e, consequentemente, melhora a qualidade de vida:

Eu acho que a gente tem que cuidar mesmo para não dar trabalho para os outros e pra gente também é bom. A biodança deixa a gente livre... A gente se solta! (Biodançante 7)

Que se você busca alimentar seu espírito, você alimenta seu corpo também. 0 momento que você sai de casa para vir para biodança é porque você tá buscando alguma coisa, uma mudança na sua vida. (Biodançante 8 )

0 processo da biodança parece substanciar a transformação pessoal nos quatro níveis - físico, mental, espiritual, social -, apresentando grande potencial formador de seres universais dotados 


\section{...o reconhecimento da biodança como uma PIC tem efeitos concretos no modo de vida das pessoas...}

de saúde e discernimento, agentes ativos de transformação cultural por meio do afeto, da reverência a todas as formas de vida e do trabalho em comunidade, com a capacidade de gerar redes de ação educativa e terapêutica mobilizadoras de crianças, jovens, adultos e anciãos para um trabalho consciente e dedicado de regeneração da vida na/ com a Terra ${ }^{28}$.

\section{CONCLUSÃO}

Os resultados sugerem que, dentro do processo de cuidado e promoção da saúde, a biodança se apresenta como importante recurso para o fortalecimento da identidade e o reconhecimento dos indivíduos, uma vez que é um sistema de desenvolvimento dos potenciais humanos.

Este estudo contribui para a ampliação do olhar ao cuidado por meio das PIC, que constitui ferramenta disponibilizada pelo SUS e que pode ser agregada ao fazer saúde. Acredita-se, portanto, que o reconhecimento da biodança como uma PIC tem efeitos concretos no modo de vida das pessoas, potencializando mudanças no estilo de vida e no resgate da identidade.

Nesse sentido, para além daquilo que foi observado no escopo da pesquisa houve a possibilidade de adentrar, por meio das vivências, e sentir a potência dessa prática e seu impacto sobre si e na vida daqueles que a praticavam, por meio de mudanças visiveis no tônus muscular, nas emoções e na forma como os biodançantes se relacionavam entre si.

Salienta-se que a pesquisa apresenta limitações no tocante à necessidade de aprofundamento da relação entre promoção da saúde e biodança, além da perspectiva não generalista que o próprio estudo traz, enfocando a representatividade que a pesquisa qualitativa viabiliza, o que pode favorecer possibilidades teóricas diversas.
É possível, pois, ratificar o papel transformador da biodança na vida de quem a pratica regularmente, contudo, salienta-se a importância de que outros estudos sejam realizados a fim de corroborar as evidências aqui descritas, possibilitando não apenas o reconhecimento da prática, mas sua maior capilarização nos espaços, particularmente os da saúde.

\section{CONTRIBUIÇÃO DAS AUTORAS}

Vanessa Bezerra da Cunha contribuiu com a realização da pesquisa, o delineamento do estudo e a redação do manuscrito. Rose Danielle de Carvalho Batista contribuiu com a revisão crítica do manuscrito. Camila Siqueira Cronemberger Freitas contribuiu com o delineamento do estudo e a revisão crítica do manuscrito.

\section{REFERÊNCIAS}

1. Ayres JRDCM. Sujeito, intersubjetividade e práticas de saúde. Ciênc Saúde Colet [serial on the internet]. 2001 [cited 2019 Nov 14];6(1):63-72. Available from: http://dx.doi.org/10.1590/s141381232001000100005

2. Teixeira CF, Solla JP. Modelo de atenção à saúde: promoção, vigilância e saúde da família. Salvador: Ed. UFBA; 2006.

3. Gomes R, Rebello LEFS, Nascimento EF, Deslandes $\mathrm{SF}$, Moreira MCN. A atenção básica à saúde do homem sob a ótica do usuário: um estudo qualitativo em três serviços do Rio de Janeiro. Ciênc Saúde Colet [serial on the internet]. 2011 [cited 2019 Dec 14];16(11):4513-21. Available from: http://dx.doi. org/10.1590/s1413-81232011001200024

4. Brasil. Declaração de Alma-Ata; Carta de 0ttawa; Declaração de Adelaide; Declaração de Sundsvall; Declaração de Santafé de Bogotá; Declaração de Jacarta; Rede de Megapaíses; Declaração do México. Brasília (DF): Ministério da Saúde; 2001.

5. Malta DC, Castro AMD. Promoção da saúde na atenção básica. Revista Brasileira de Saúde da Família [serial on the internet]. 2009 [cited 2019 Dec 14];10(23). Available from: http://bvsms.saude. gov.br/bvs/periodicos/revista brasiliera saude familia n23 2009.pdf

6. Brasil. Portaria MS/GM n. 687, de 30 de março de 2006. Brasília (DF): Ministério da Saúde; 2006.

7. Calado K. Biodança no SUS [document on the internet]. 2018 [cited 2018 Aug 14]. Available from: http://redehumanizasus.net/biodanca-no-sus/ 
8. D'Alencar BP, Mendes MMR, Bessa Jorge MS, Rodrigues MSP. Significado da biodança como fonte de liberdade e autonomia na auto-reconquista no viver humano. Texto \& Contexto Enferm [serial on the internet]. 2006 [cited 2019 Jul 14];15(Spec):4854. Available from: http://www.scielo.br/pdf/tce/ v15nspe/v15nspea05.pdf

9. Minayo MCDS, organizer. Pesquisa social: teoria, método e criatividade. 21. ed. Petrópolis, RJ: Vozes; 2002.

10. Gil AC. Como elaborar projetos de pesquisa. 4. ed. São Paulo: Atlas; 2008.

11. Bardin L. Análise de conteúdo. 70. ed. São Paulo: Ed. $70 ; 2011$.

12. Brasil. Resolução n. 466, de 12 de dezembro de 2012. Brasília (DF): Conselho Nacional de Saúde; 2018.

13. Brasil. Resolução n. 510, de 7 de abril de 2016. Brasília (DF): Conselho Nacional de Saúde; 2016.

14. Ciampa ADC. Psicologia social: o homem em movimento. São Paulo: Brasiliense; 1984.

15. Ferreira EM. Biodanza e a expressão da identidade: dançando os critérios da identidade saudável em ambiente hostil [monograph]. Rio de Janeiro: International Biocentric Foundation; 2012.

16. Santos MLP, Alberti AM, Retamosa GE, Rivera FJF, Acácio JDS, Lobo T. Biodanza clínica: atenção à saúde e cuidado com a vida. Belo Horizonte: [name unknown]; 2013.

17. Juan CA, Fernandez R, Afonso DS, Daniele PS. Religião e saúde: para transformar ausências em presenças. Saúde Soc [serial on the internet]. 2018 [cited 2020 Nov 14];27(4). Available from: https:// www.scielosp.org/article/sausoc/2018.v27n4/1058$1070 /$

18. Oliveira MRD, Junges JR. Saúde mental e espiritualidade/religiosidade: a visão de psicólogos. Estud Psicol (Natal) [serial on the internet]. 2012 [cited 2019 Dec 14];17(3). Available from: http://www.scielo.br/scielo.php?script=sci arttext\&pid $=$ S1413-294X2012000300016

19. Pretty MEI, Zuñiga MIG, Urrutia SHS, Solis VDG, Osorio LAG, González MEC. Biodanza en adultos mayores con enfermedades crónicas para la promoción de la salud. Arch Med [serial on the internet]. 2019 [cited 2019 Dec 14];19(1). Available from: https:// www.redalyc.org/jatsRepo/2738/273859249006/ html/index.html

20. Teixeira IMDC, Oliveira MWD. Práticas de cuidado à saúde de mulheres camponesas. Interface Comun Saúde Educ [serial on the internet]. 2014 [cited 2019 Nov 14];2(18). Available from: http://www.scielo. $\mathrm{br} / \mathrm{pdf} / \mathrm{icse} / \mathrm{v} 18 \mathrm{~s} 2 / 1807-5762$-icse-18-s2-1341.pdf
21. Mendes R, Fernandez JCA, Sacardo DP. Promoção da saúde e participação: abordagens e indagações. Saúde Debate [serial on the internet]. 2016 [cited 2020 Nov 14];40(108):190-203. Available from: http://www.scielo.br/scielo.php?script=sci arttext\&pid $=$ S0103-11042016000100190\&lng $=e n$

22. Czeresnia D. 0 conceito de saúde e a diferença entre prevenção e promoção. In: Czeresnia D, Freitas CM, organizers. Promoção da saúde: conceitos, reflexões, tendências. Rio de Janeiro: Fiocruz; 2003. p. 39-53.

23. Ayres JRDCM. Sujeito, intersubjetividade e práticas de saúde. Ciênc Saúde Colet [serial on the internet]. 2001 [cited 2019 0ct 14];6(1). Available from: http://www.scielo.br/scielo.php?pid=S1413$\underline{81232001000100005 \& s c r i p t=s c i ~ a b s t r a c t \& t \operatorname{lng}=p t}$

24. Lopes AAF. Cuidado e empoderamento: a construção do sujeito responsável por sua saúde na experiência do diabetes. Saúde Soc [serial on the internet]. 2015 [cited 2019 Dec 14];24(2). Available from: http://www.scielo.br/scielo.php?pid=S0104$12902015000200486 \&$ script $=s c i$ abstract \&t $\operatorname{lng}=p t$

25. Silva H. A biodanza um caminho para a vitalidade [monograph]. Lisboa: Escola de Biodanza de Lisboa; 2014.

26. Góis CWDL, Ribeiro KG. Biodança, saúde e qualidade de vida: uma perspectiva integral do organismo. Pensamento Biocêntrico [serial on the internet]. 2008 [cited 2019 Aug 14];(10):43-65. Available from: http://www.pensamentobiocentrico. com.br/content/edicoes/revista-10-03.pdf

27. Dias AMDS. A po-ética do encontro humano: um estudo da biodanza como mediação da educação biocêntrica na transformação do emocionar para novas posturas éticas [thesis]. João Pessoa: Universidade Federal da Paraíba; 2013.

28. Freitas F. Consciência e biodanza: epistemologia e vivência para o ser universal [monograph]. Belo Horizonte: Escola de Biodanza Sistema Rolando Toro de Belo Horizonte; 2009.
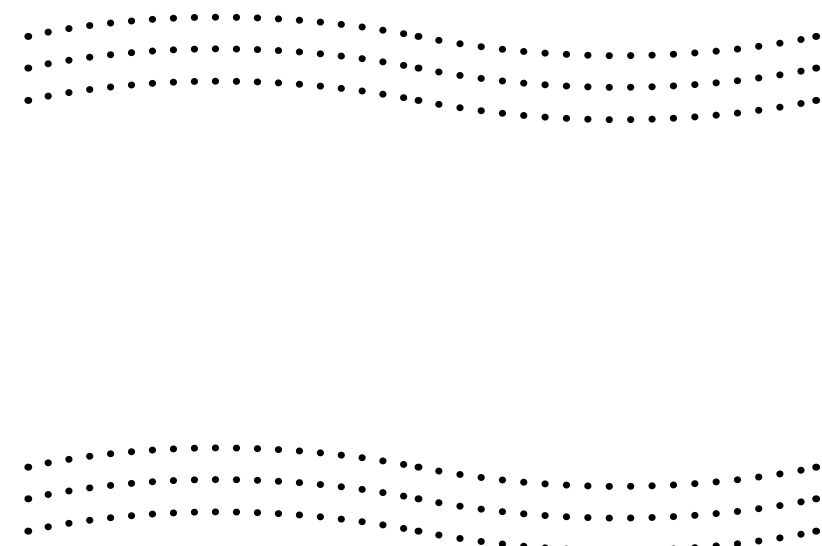